\title{
Carnitine palmitoyltransferase II deficiency
}

INSERM

\section{Source}

INSERM. (1999). Orphanet: an online rare disease and orphan drug data base. Carnitine palmitoyltransferase // deficiency. ORPHA:157

Carnitine palmitoyltransferase II (CPT II) deficiency is an inherited metabolic disorder that affects mitochondrial oxidation of long chain fatty acids (LCFA). Three forms of CPT II deficiency have been described: a myopathic form, a severe infantile form and a neonatal form (see these terms). 